\title{
Formaldehyde Adsorption into Clinoptilolite Zeolite Modified with the Addition of Rich Materials and Desorption Performance Using Microwave Heating
}

\author{
Amin Kalantarifard, Jo Gwang Gon, and Go Su Yang * \\ Department of Environmental Engineering, Chonbuk National University, Jeonju, Republic of Korea
}

Received 19 November 2015, revised 4 May 2016, accepted 28 May 2016

\begin{abstract}
Granite, bentonite, and starch were mixed with clinoptilolite zeolite to produce a modified zeolite. The modified zeolite was tested for its ability to absorb formaldehyde from air. The modified sample formaldehyde adsorption capacity was then compared with those of commercially available clinoptilolite, faujasite (Y), mordenite, and zeolite type A. Studies were focused on the relationships between the physical characteristics of the selected zeolites (crystal structure, surface porosity, pore volume, pore size) and their formaldehyde adsorption capacity. The removal of starch at high temperature $\left(1100^{\circ} \mathrm{C}\right)$ and addition of bentonite during modified clinoptilolite zeolite (M-CLZ) preparation generated large pores and a higher pore distribution on the sample surface, which resulted in higher adsorption capacity. The formaldehyde adsorption capacities of M-CLZ, clinoptilolite, faujasite (Y), zeolite type A, and mordenite were determined to be 300.5, 194.5, 123.7, 106.7, and 70 mg per gram of zeolite, respectively. The M-CLZ, clinoptilolite, and faujasite (Y) crystals contained both mesoporous and microporous structures, which resulted in greater adsorption, while the zeolite type A crystal showed a layered structure and lower surface porosity, which was less advantageous for formaldehyde adsorption. Furthermore, zeolite regeneration using microwave heating was investigated focusing on formaldehyde removal by desorption from the zeolite samples. XRD, XRF, $\mathrm{N}_{2}$ adsorption/desorption, and FE-SEM experiments were performed to characterize the surface structure and textural properties the zeolites selected in this study.
\end{abstract}

Key words: Modified zeolites, Rich rocks, Surface structure, Formaldehyde adsorption/desorption

Citation: Kalantarifard, A., J. G. Gon, and G. S. Yang, 2016: Formaldehyde adsorption into clinoptilolite zeolite modified with the addition of rich materials and desorption performance using microwave heating. Terr. Atmos. Ocean. Sci., 27, 865-875, doi: 10.3319/TAO.2016.05.28.01(TT)

\section{INTRODUCTION}

Formaldehyde, one of the most important volatile organic compounds (VOCs), has been classified as a carcinogen that can cause nasopharyngeal cancer in humans and plays a key role as an intermediate in the tropospheric photochemical oxidation of hydrocarbons (Solomon et al. 2008; Wisthaler et al. 2008). Formaldehyde is a byproduct emitted mainly from the combustion of waste wood, furniture and medium-density fiberboard (MDF) panels (Hedberg et al. 2002). Burning sensations in the eyes, nose and throat are the effects of formaldehyde when its concentration exceeds $0.1 \mathrm{ppm}$ in the atmosphere. Therefore, it is a matter of urgency to decrease the concentration of this gas before it is

\footnotetext{
* Corresponding author

E-mail: gsyang@jbnu.ac.kr
}

emitted into the atmosphere.

Among the techniques used to reduce formaldehyde in the atmosphere, adsorption has been considered by many researchers due to its higher efficiency and lower operational cost (Góra-Marek and Datka 2008; Ma et al. 2011; Chen et al. 2014). Zeolites are common adsorbents used in this process because of advantages that include high adsorption capacity, stability at high temperatures and the possibility of regeneration. It has been shown that the performance of zeolites for VOC adsorption depends largely on the shape of the mesopores and the pore size in zeolite crystal networks (Johnson et al. 1997; Babarao et al. 2011). The presence of alumina and cations such as $\mathrm{Ca}^{+}, \mathrm{K}^{+}$, and $\mathrm{Na}^{+}$influence the zeolite composition, which changes the pore diameter and surface area of zeolite structures (Frising and Leflaive 2008; Legras et al. 2012; Newsome and Coppens 2015). If 
the zeolite structure pore diameter is smaller than the kinetic diameter of a selected gas, the adsorption capacity of that zeolite will be lower than that of zeolites with larger pore sizes (Cazorla A. and Grutzeck 2012; Kim and Ahn 2012; Solanki and Zaman 2012).

Zeolite synthesis has been suggested to achieve better adsorption capability. Zeolite synthesis is usually accomplished through the addition of different elements to the zeolite structure or through temperature variation during zeolite production. Synthesized zeolites usually show higher adsorption capacity and stable physico-chemical properties after the desorption process. Previous authors (Cazorla A. and Grutzeck 2012) have studied the efficiency of synthesized zeolites produced by mixing waste products from combusted coal, metakoalinite, and sodium hydroxide for formaldehyde adsorption. Their results showed that samples prepared with a low concentration of metakoalinite and a stronger $\mathrm{NaOH}$ solution appeared to have a cubic crystalline structure and a very porous surface with relatively higher adsorption capacity. The curing temperature for these zeolite samples was $185^{\circ} \mathrm{C}$ over $36 \mathrm{~h}$, resulting in larger crystal growth and a hexagonal shape, which also had a positive effect on formaldehyde adsorption. Zheng et al. (2012) studied the activation and organic modification of stellerite zeolite to improve formaldehyde adsorption. The results showed that zeolite sample calcination at $300^{\circ} \mathrm{C}$ for $1.5 \mathrm{~h}$ had a positive effect on formaldehyde adsorption capacity, although excessively increasing the calcination time decreased the adsorption capacity due to zeolite structure decomposition and decreased specific surface area. The maximum formaldehyde adsorption capacity of the calcined organic modified zeolite reached $1.84 \mathrm{mg} \mathrm{g}^{-1}$ of zeolite. Ichiura et al. (2003) showed efficient formaldehyde adsorption into a composite $\mathrm{TiO}_{2}$-zeolite $\mathrm{Y}$ sheet and desorption using UV irradiation. The composite sheets were heated in an electronic furnace at $700^{\circ} \mathrm{C}$ for $20 \mathrm{~min}$ to remove impurities from the zeolite framework, which appeared during the preparation process. It was found that the composite $\mathrm{TiO}_{2}$-zeolite $\mathrm{Y}$ sheet removed formaldehyde more efficiently than a simple $\mathrm{TiO}_{2}$ sheet due to continuous formaldehyde decomposition from the composite sheet by UV irradiation in the presence of a $\mathrm{TiO}_{2}$ photo catalyst.

Modified clinoptilolite zeolite (M-CLZ) with a large pore surface structure was prepared in this study through the addition of alkaline earth metals, bentonite, starch and granite. A detailed study evaluating the zeolite surface structure effect on formaldehyde adsorption behavior was performed. Thermal treatment of modified zeolite containing starch showed starch elimination from the zeolite structure at high temperature, resulting in large surface pores and large internal channels. A comparison between the modified zeolite and commercially available clinoptilolite, faujasite (Y), zeolite type A, and mordenite showed that the formaldehyde adsorption capacity of the modified sample was relatively higher due to good pore distribution on the surface and their interconnections with the internal zeolite structure cavities. Additionally, microwave energy was used to remove the adsorbed formaldehyde for effective adsorbent reuse.

\section{EXPERIMENTAL}

\subsection{Materials}

Acetic acid, aluminum oxide, starch, carboxymethyl cellulose, and formaldehyde were purchased from Sigma Aldrich. Starch, bentonite (Bri-chem, USA) and granite (Gwahaknara, South Korea) in the presence of $25 \mathrm{~mL}$ deionized water were used to modify the clinoptilolite crystal structure. Clinoptilolite zeolite, zeolite type A, faujasite (Y), and mordenite were purchased from a commercial source and used as received.

\subsection{Characterization}

Nitrogen adsorption/desorption isotherms were measured at $-196^{\circ} \mathrm{C}$ with an ASAP 2020 analyzer (Micrometric, USA). The The Brunauer-Emmett Teller (BET) surface area and sample pore volume during adsorption/desorption experiments were measured based on t-plot analysis. X-ray fluorescence (XRF) spectroscopy using a Philips - PW 148D was used for zeolite sample elemental analysis. X-ray diffraction (XRD) was carried out using a Rigaku X-ray diffractometer (Cu Ka., $\lambda=1.54059 \AA$ ) over Bragg angles ranging from $10-50^{\circ}$ to identify the crystal structure composition. Sample surface morphologies were monitored using field emission scanning electron microscopy (FE-SEM), model Zeiss Supra 40 VP. In the desorption experiment conducted with microwaves, a commercial microwave heating system (Korea microwave instrument) was used with an output power of $2.45 \mathrm{GHz}$ and $500 \mathrm{~W}$.

\subsection{Zeolite Preparation}

M-CLZ were prepared by crushing $1.0 \mathrm{~g}$ of cleaned natural zeolite (clinoptilolite) into powder and dispersing it in 1 mole of $\mathrm{M}_{\mathrm{E}} \mathrm{CH}_{3} \mathrm{COOH}\left(\mathrm{M}=\mathrm{Na}^{+}, \mathrm{Ca}^{+}\right.$, and $\mathrm{K}^{+}$). The solution was then heated at $90^{\circ} \mathrm{C}$ for $24 \mathrm{~h}$. The obtained slurry was filtered in a vacuum flask. The zeolite produced after the addition of alkaline earth metals was named $\mathrm{M}-\mathrm{CLZ} \mathrm{Z}_{\alpha}$. The M-CLZ $\mathrm{M}_{\alpha}$ surface pores and crystal structure were then modified by adding alumina (10 wt $\%$ ), starch $(20 \mathrm{wt} \%)$, bentonite $(10 \mathrm{wt} \%)$, and granite $(10 \mathrm{wt} \%)$ in $25 \mathrm{~mL}$ of de-ionized water inside an oven at $25^{\circ} \mathrm{C}$. The addition of granite increased the zeolite structure hardness. The presence of fluxing ions improved the zeolite sample bulk density, while bentonite crystal acted like a sponge and increased the number of internal cavities in the final product (Kayabalı and Kezer 1998; El-Maghraby et al. 2011; Naga et al. 2012). The obtained sample was manually formed into a 
spherical shape with an outer diameter of about $\Phi=4 \sim 6 \mathrm{~mm}$. Carboxymethyl cellulose was used as a binder during the mixing process. The sample was then placed into an electronic furnace at $1100^{\circ} \mathrm{C}$ for $5 \mathrm{~min}$, then cooled to room temperature before the calcination process. This is considered sufficient time to quickly remove the starch from the surface and internal cavities in the zeolite structure without changing the structural framework and consequently improves the zeolite micro- and mesoporicity (İzci and İzci 2007). The dried sample calcination occurred under a mixed gas atmosphere of air and nitrogen at a ratio of $70-30 \%$. The calcination temperature was increased at $10^{\circ} \mathrm{C} \mathrm{min}^{-1}$ over $5 \mathrm{~h}$ from room temperature to $550^{\circ} \mathrm{C}$. The $5 \mathrm{~h}$ calcination process provides conditions where both the organic matter and impurities still present in the sample are removed by shifting to an injected nitrogen and air atmosphere. The final product after thermal treatment was named M-CLZ.

Commercially available clinoptilolite, faujasite (Y), zeolite type A, and mordenite had outer diameters of approximately $\Phi=2 \sim 3 \mathrm{~mm}$. The zeolite water content was determined based on weight loss after thermal treatment in an electronic furnace at $300^{\circ} \mathrm{C}$ for $24 \mathrm{~h}$. Figure 1 shows photographic images of the samples prepared in this study.

\subsection{Apparatus and Procedures}

A quartz tube (diameter $10 \mathrm{~mm}$ and length $50 \mathrm{~mm}$ ) containing $50 \mathrm{mg}$ of zeolite sample was placed horizontally at the center of a microwave oven. The zeolite samples were embedded between two pieces of wool and fixed in the proper location inside the quartz tube. A reservoir containing formaldehyde liquid was kept in a conventional oven at a constant temperature of $25^{\circ} \mathrm{C}$. Nitrogen as a carrier gas passed through the bubbler in the reservoir to constantly produce tiny gas bubbles. The formaldehyde concentration generated by passing $\mathrm{N}_{2}$ at $50 \mathrm{ml} \mathrm{min}^{-1}$ into the formaldehyde liquid reservoir was measured as $884 \mu \mathrm{g} \mathrm{min}^{-1}$ (GC-FPD, Shimadzu model GC-17A). Increasing the $\mathrm{N}_{2}$ flow rate to $80 \mathrm{ml} \mathrm{min}^{-1}$ or decreasing it to $20 \mathrm{ml} \mathrm{min}{ }^{-1}$ had a negative effect on gas generation, followed by decreases in the outlet gas concentration. The gas mass balance in the constant $\mathrm{N}_{2}$ flow rate $\left(50 \mathrm{ml} \mathrm{min}^{-1}\right)$ was applied to determine the adsorption rate per gram of zeolite as a function of time. During the experiment the tubing was wrapped with heating tape and insulation tape to prevent vapor from condensing on the inner tubing surfaces. Figure 2 shows the laboratory-scale experimental setup used to measure the adsorption/desorption of formaldehyde for the zeolite samples. The adsorption capacity of the samples was measured by passing the mixed gas through the quartz tube containing the zeolite sample. The quartz tube outlet was attached to a GC-FPD to measure the amount of adsorbed formaldehyde in the zeolite as a function of time and obtain a gas adsorption breakthrough curve for the selected zeolite sample. The maximum adsorp- tion capacity of every sample was determined using the total sample adsorption time, normalized by the sample weight (50 mg).

\section{RESULTS AND DISCUSSION}

XRF analysis was used to determine the zeolite sample composition. Table 1 shows the physical and chemical characteristics of the zeolite samples and their formaldehyde adsorption capacities. The Si/Al ratio for zeolite type A was approximately 1 , while mordenite zeolite showed a relatively higher value of 5.8. Table 1 clearly shows that the addition of bentonite, granite, and alkaline earth metals during M-CLZ preparation resulted in a higher percentage of cations in the zeolite framework. The bentonite and granite chemical characterizations used to modify the clinoptilolite zeolite were determined with XRF. The results are shown in supplementary data Table S1. The existence of these cations in the zeolite framework balances the negative charges introduced by aluminum atoms that possess acidic or basic character of zeolites. The acidic or basic character of zeolites directly affects VOC adsorption performance (Barthomeuf 2003; Koriabkina et al. 2005; Walton et al. 2006).

XRD patterns of the zeolite samples are presented in Fig. 3. XRD results for commercial zeolite samples showed similar patterns as those obtained with the joint committee of powder diffraction standard powder diffraction database file and previous studies (Treacy and Higgins 2007; Teber et al. 2010). Peaks typical of zeolite type A were found at $2 \theta=7.1^{\circ}, 10.1^{\circ}, 22.4^{\circ}$, and $27.1^{\circ}$ (Sharma et al. 2012; Bieseki et al. 2013). XRD results for zeolite type A showed the existence of feldspar in the zeolite structure due to the appearance of XRD peaks at $2 \theta=16.2^{\circ}$ and $34.3^{\circ}$ (Zheng et al. 2012). The reflections at $2 \theta=20.8^{\circ}$ and $26.6^{\circ}$ in faujasite (Y) and mordenite zeolite showed a large quantity of quartz and a smaller amount of feldspar compared to zeolite type A (Szostak 1998; Mohamed et al. 2005; Bieseki et al. 2013). High-intensity M-CLZ peaks were found at $2 \theta=10.8^{\circ}$, $22.7^{\circ}, 24.5^{\circ}$, and $30.3^{\circ}$, which correspond to the existence of clinoptilolite zeolite in the sample (Muir et al. 2016). The mineralogical behavior of M-CLZ due to the addition of bentonite and granite during the preparation process caused the appearance of minerals such as anothite and albite peaks in the XRD diffractions. Previous studies showed that bentonite and granite contain considerable amounts of albite and anorthite, which relatively affect the XRD patterns (Wirsching 1981; Yildiz et al. 1999; Y1lmaz et al. 2007). The albite peak was observed at $2 \theta=21.8^{\circ}, 23.9^{\circ}, 35.2^{\circ}$, while the anorthite peak was observed at $2 \theta=14.1^{\circ}, 28.15^{\circ}$, and $39.2^{\circ}$ (Varela et al. 2006; Dávila-Rangel et al. 2007).

$\mathrm{N}_{2}$ adsorption/desorption isotherm experiments on the selected zeolites were measured at $-196^{\circ} \mathrm{C}$, with the results shown in Fig. 4 and textural properties summarized in Table 2. According to the Brunauer-Deming-Deming-Teller 

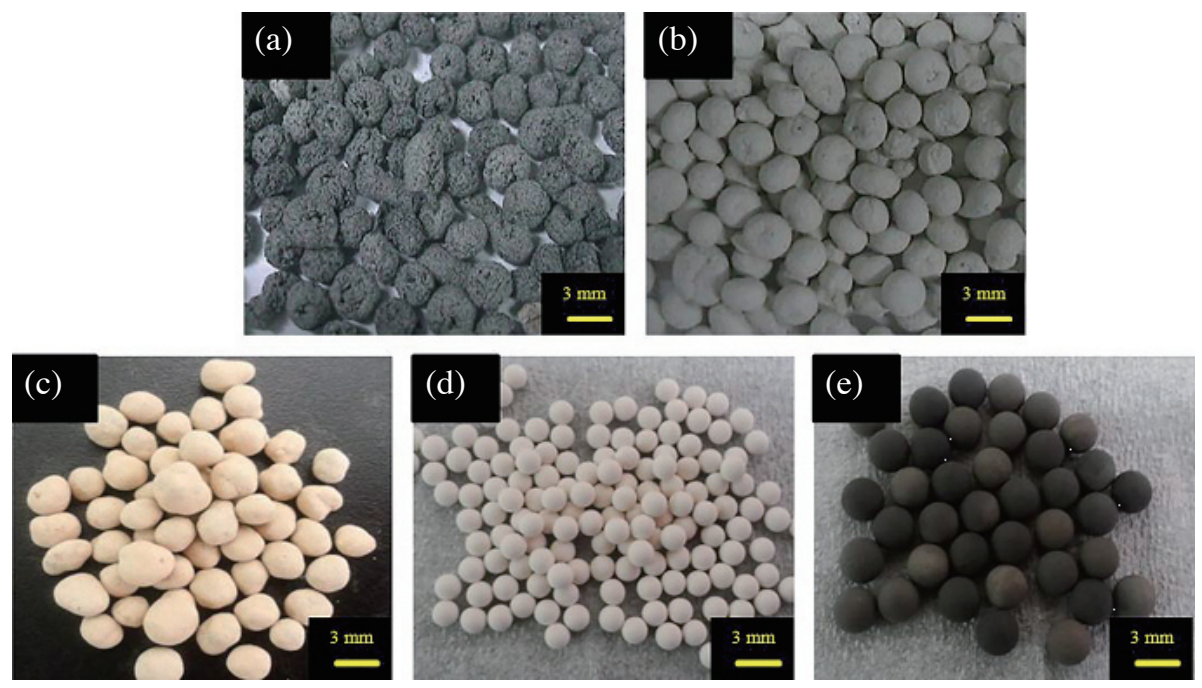

Fig. 1. Photographic images of zeolite samples used in this study. (a) Modified clinoptilolite zeolite (M-CLZ), (b) Clinoptilolite zeolite, (c) Faujasite (Y) zeolite, (d) Zeolite type A, (e) Mordenite zeolite. (Color online only)

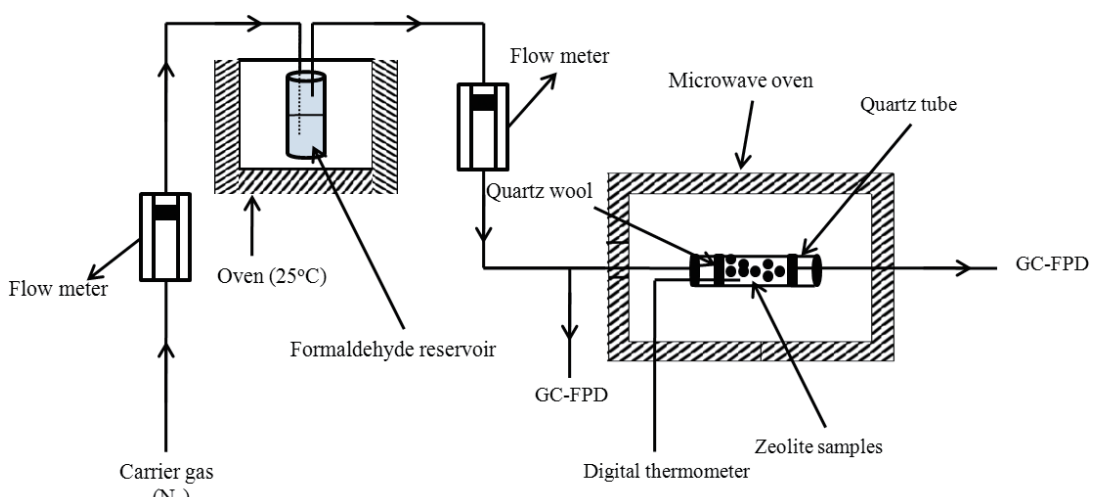

Fig. 2. Laboratory-scale experimental setup used to measure the adsorption/desorption of formaldehyde in selected zeolites. Experimental conditions: normal pressure, oven temperature $25^{\circ} \mathrm{C}$, carrier gas flow rate $(50 \mathrm{ml} \mathrm{min}-1)$, and $50 \mathrm{mg}$ of adsorbent materials. (Color online only)

Table 1. Physical and chemical characterization of mordenite, zeolite type A, faujasite (Y), clinoptilolite, and M-CLZ using X-ray fluorescence (XRF) and formaldehyde adsorption capacity.

\begin{tabular}{|c|c|c|c|c|c|c|c|c|c|}
\hline \multirow{2}{*}{ Zeolites } & $\mathrm{SiO}_{2}$ & $\mathrm{Al}_{2} \mathrm{O}_{3}$ & $\mathrm{Fe}_{2} \mathrm{O}_{3}$ & $\mathrm{CaO}$ & $\mathrm{Na}_{2} \mathrm{O}$ & $\mathrm{K}_{2} \mathrm{O}$ & $\mathbf{P}_{2} \mathbf{O}_{5}$ & $\mathrm{H}_{2} \mathrm{O}$ & \multirow{2}{*}{$\begin{array}{l}\text { Adsorption capacity } \\
\qquad\left(\mathrm{mg} \mathrm{g}^{-1}\right)\end{array}$} \\
\hline & \multicolumn{8}{|c|}{$(\mathrm{wt} \%)$} & \\
\hline Mordenite & 79.80 & 13.76 & 1.3 & 0.8 & 0.8 & 1.2 & 0.03 & 2.31 & 70 \\
\hline ZeoliteType A & 40.84 & 40.83 & 0.8 & 0.2 & 9.2 & 0.1 & 0.03 & 8.0 & 106.7 \\
\hline Faujasite (Y) & 76.86 & 14.24 & 0.06 & 0.1 & 4.2 & 1.5 & 1.74 & 1.3 & 123.7 \\
\hline Clinoptilolite & 68.91 & 29.97 & 0.08 & 0.02 & 0.01 & 0 & 0.01 & 1.0 & 194.5 \\
\hline M-CLZ & 51.16 & 34.11 & 0.03 & 1.4 & 7.4 & 3.6 & 2.3 & 0 & 300.5 \\
\hline
\end{tabular}

Table S1. Chemical characterization of bentonite and granite used to modify the clinoptlolite zeolite.

\begin{tabular}{c|c|c|c|c|c|l|l|l}
\hline & $\mathbf{S i}$ & $\mathbf{A l}$ & $\mathrm{Fe}_{2} \mathbf{O}_{3}$ & $\mathbf{C a O}$ & $\mathbf{N a}_{2} \mathbf{O}$ & $\mathbf{K}_{2} \mathbf{O}$ & $\mathbf{P}_{2} \mathbf{O}_{5}$ & $\mathbf{H}_{2} \mathbf{O}$ \\
\cline { 2 - 9 } & \multicolumn{8}{c}{$(\mathbf{w t} \%)$} \\
\hline Bentonite & 55.92 & 16.2 & 0.02 & 1.56 & 6.6 & 4.1 & 4.2 & 11.4 \\
Granite & 63.3 & 14.3 & 0.06 & 1.84 & 5.4 & 5.74 & 3.31 & 6.05 \\
\hline
\end{tabular}




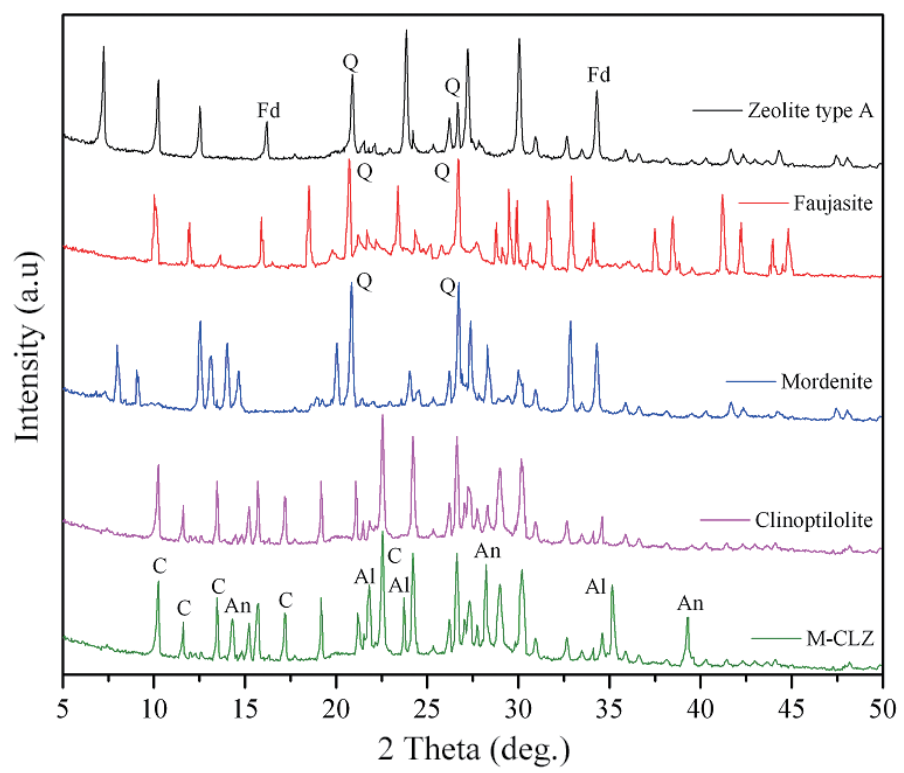

Fig. 3. The XRD patterns of modified clinoptilolite (M-CLZ, after addition of bentonite and granite) and various other zeolites (Fd: feldspar; Q: quartz; C: clinoptilolite; An: anorthite; Al: Albite). (Color online only)

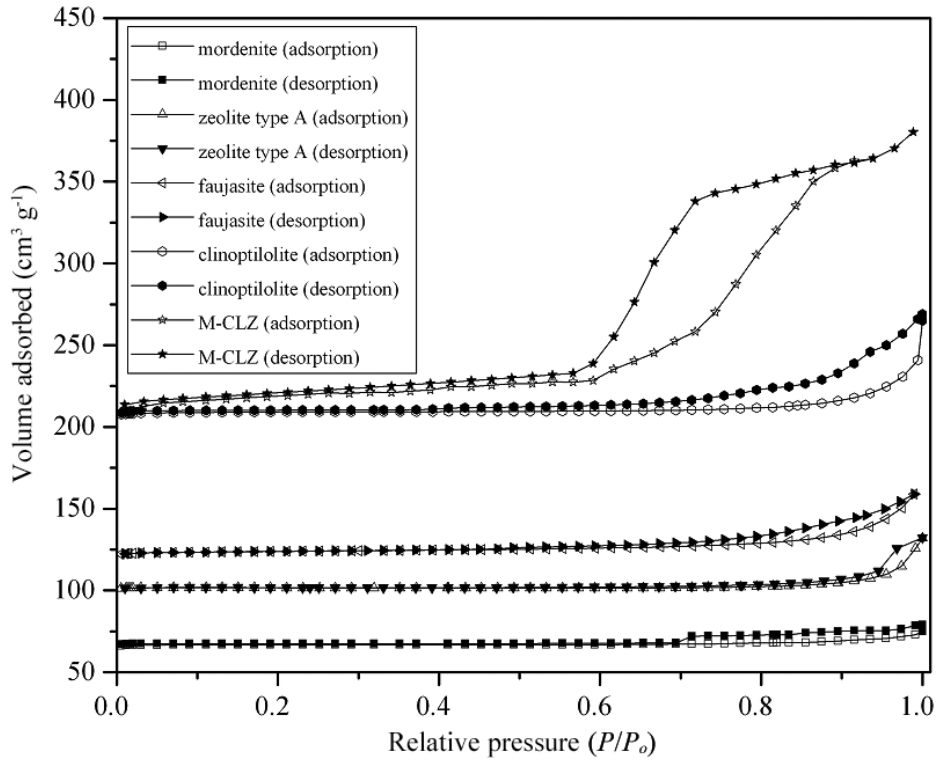

Fig. 4. Physical characteristics of various zeolites obtained from $\mathrm{N}_{2}$ gas adsorption/desorption at $-196^{\circ} \mathrm{C}$.

Table 2. Textural properties of the selected zeolites in this study.

\begin{tabular}{c|c|c|c|c}
\hline \multirow{2}{*}{ Zeolites } & \multirow{2}{*}{$\mathbf{S}_{\text {BET }}{ }^{\mathbf{a}}\left(\mathbf{m}^{2} \mathbf{g}^{-1}\right)$} & \multicolumn{3}{|c}{ Pore volume $\left(\mathbf{c m}^{\mathbf{3}} \mathbf{g}^{-1}\right)$} \\
\cline { 3 - 5 } & & $\mathbf{V}_{\text {total }}{ }^{\mathbf{b}}$ & $\mathbf{V}_{\text {micro }}{ }^{\mathbf{c}}$ & $\mathbf{V}_{\text {meso }}{ }^{\mathbf{c}}$ \\
\hline Mordenite & 253.3 & 0.064 & 0.051 & 0.018 \\
Zeolite type A & 301.6 & 0.107 & 0.128 & 0.022 \\
Faujasite (Y) & 415.2 & 0.136 & 0.101 & 0.05 \\
Clinoptilolite & 436.3 & 0.270 & 0.143 & 0.078 \\
M-CLZ & 663.2 & 0.298 & 0.237 & 0.192 \\
\hline
\end{tabular}

Note: a: Brunauer-Emmett Teller method; $b$ : Volume adsorbed at $P / P_{o}=0.99 ; c:$ Measured using the t-plot method. 
(BDDT) classification, mordenite shows a micro porous, type 1 surface structure. The predominant adsorption on mordenite finishes below $\mathrm{P} / \mathrm{P}_{0}=0.5$ with no distinction at high pressure, indicating the absence of a hysteresis loop. The BET results confirm that the majority of the surface area $\left(253.3 \mathrm{~m}^{2} \mathrm{~g}^{-1}\right)$ is micro porous, while the mesoporosity contribution $\left(0.018 \mathrm{~cm}^{2} \mathrm{~g}^{-1}\right)$ is relatively small. The isotherms of zeolite type A, faujasite (Y), and clinoptilolite resembled type IV, which shows the coexistence of mesoporous and microporous structures. A vertical hysteresis loop associated with capillary condensation at high pressure $\mathrm{P}_{0}=0.7$ to 0.99 indicates the presence of limited mesoporous volumes for these samples. Clinoptilolite zeolite had a high proportion of mesoporous surface $\left(0.078 \mathrm{~cm}^{3} \mathrm{~g}^{-1}\right)$ compared to zeolite type $\mathrm{A}\left(0.022 \mathrm{~cm}^{3} \mathrm{~g}^{-1}\right)$ and faujasite $(\mathrm{Y})\left(0.05 \mathrm{~cm}^{3} \mathrm{~g}^{-1}\right)$, in agreement with the BET results (Table 2). The maximum specific area was observed for M-CLZ and was found to be $663.2 \mathrm{~m}^{2} \mathrm{~g}^{-1}$, the total pore volume and mesoporous volume for this sample were 0.298 and $0.192 \mathrm{~cm}^{3} \mathrm{~g}^{-1}$, respectively. In general, M-CLZ showed the co-presence of microporous and mesoporous structures. The presence of large pore diameter distribution due to the removal of starch at high temperature and the addition of bentonite on the M-CLZ surface were indicated by the sharp inflection at the relative pressure $\left(\mathrm{P} / \mathrm{P}_{0}\right)$ between 0.6 and 0.9 , which confirmed the mesoporous structure of the sample at high pressure and the type IV zeolite isotherm.

The surface morphologies of selected zeolites were evaluated using FE-SEM, with the images shown in Fig. 5. The M-CLZ (Fig. 5a) image shows a very frequent distribution and large number of surface pores, indicating that thermal treatment at $1100^{\circ} \mathrm{C}$ and starch removal from the sample caused the appearance of large surface pores, which were observed to be between 1 - $4 \mu \mathrm{m}$. The presence of pores on the surface during zeolite crystal formation significantly improved the formaldehyde adsorption capacity of this sample. FE-SEM images of the clinoptilolite and faujasite $(\mathrm{Y})$ zeolites in Figs. 5b and c show surface pore sizes between $1-2 \mu \mathrm{m}$, while the number of pores on the faujasite (Y) surface was relatively lower than that on clinoptilolite. The zeolite type A surface image (Fig. 5d) shows the existence of a layered structure with different shaped grooves, which significantly affected the adsorption capacity. FE-SEM images of the mordenite zeolite in Fig. 5e show a mixedphase crystal structure. We postulate that the existence of very small spherical particles $(\sim 50 \mathrm{~nm})$ possibly led to pore destruction on the surface. During the experiment we also observed the agglomeration of these particles in many areas of the zeolite crystal. This phenomenon would decrease the sample active surface sample during the adsorption process because most of the pores are covered with small particles. This assumption was confirmed with the low adsorption capacity of mordenite zeolite compared to that of the other types of zeolite.

\subsection{Adsorption/Desorption Performance}

Formaldehyde adsorption breakthrough curves with various zeolites are shown in Fig. 6. A longer breakthrough time or saturation time reflects a greater adsorption capacity. All of the selected zeolites reached adsorption equilibrium, but the breakthrough times were generally different. Among the samples, M-CLZ had the longest breakthrough time (17 min), while mordenite had the shortest breakthrough time (5 min). Zeolite type A and faujasite (Y) showed almost similar adsorption capacities. The maximum formaldehyde adsorption for these samples was obtained after 6 and $7 \mathrm{~min}$ of contact time. The adsorption capacity of clinoptilolite zeolite was superior to that of mordenite, zeolite type A, or faujasite (Y). Clinoptilolite zeolite reached maximum adsorption after $11 \mathrm{~min}$. The XRF results in Table 1 show that zeolite type A and mordenite consisted of the lowest and highest $\mathrm{Si} / \mathrm{Al}$ ratios (1 and 5.8), but their adsorption capacities were lower than that of M-CLZ zeolite with $\mathrm{Si} / \mathrm{Al}$ ratios of (1.5). In other words, the formaldehyde adsorption capacity of the selected zeolites did not appear to be influenced by the $\mathrm{Si} / \mathrm{Al}$ ratio. The textural properties and crystal structure of zeolites therefore seem to be the main adsorption capacity factors. Normalizing the total adsorption time for the samples using sample weight $(50 \mathrm{mg})$, the formaldehyde adsorption capacities of M-CLZ, clinoptilolite, faujasite $(\mathrm{Y})$, zeolite type $\mathrm{A}$, and mordenite were determined to be $300.5,194.5,123.7,106.7$, and $70 \mathrm{mg}$ per gram of zeolite, respectively. The formaldehyde adsorption capacity in M-CLZ showed a relatively higher value compared to that of the other zeolites, which resulted from the extensive pore distribution on the M-CLZ surface and the highly crystallized, large internal channel sizes due to the addition of alkaline earth metals, bentonite, and granite. This result is also illustrated by the high calculated BET values and in the FE-SEM images.

Microwave desorption has been considered in this research to desorb formaldehyde from samples within a short time because the desorption efficiency of this method on polar molecules such as formaldehyde is greater than that of non-polar VOCs (Zheng et al. 2012; Muir et al. 2016; Yang 2016). Formaldehyde has polarity because it has permanent dipoles with a triagonal planer molecular geometry and a symmetrical charge distribution. The microwave irradiation time effect on increasing the zeolite sample temperature bed is shown in Fig. 7. The zeolite temperature profile during microwave heating was obtained with a digital thermometer. The absorption bed temperature for zeolite type A and mordenite rose quickly after 10 min of microwave irradiation and reached $180^{\circ} \mathrm{C}$. The maximum temperatures obtained by these samples were 380 and $355^{\circ} \mathrm{C}$ after $1 \mathrm{~h}$. The higher percentage of water and ferrous compounds in the zeolite structures significantly increase the absorbed heat during microwave irradiation time. Water may absorb microwaves 
due to the polarization induced by the external oscillating electronic field in a microwave oven. Water molecules consist of two $\mathrm{OH}$ covalent polar bonds with the tendency of the four oxygen electron pair, resulting in a polar molecule with a "V" shape (Kaatze et al. 2002; Omisanya et al. 2012). The water contents for mordenite, zeolite type A, faujasite (Y), clinoptilolite, and M-CLZ were 2.31, 8, 1.3, 1.0, and zero percent (Table 1). The higher water contents of zeolite type A and mordenite caused a faster increase in temperature for these samples at the beginning of the experiment. The temperature reached $100^{\circ} \mathrm{C}$ after $5 \mathrm{~min}$. Water included in the zeolite framework vaporized between $100-105^{\circ} \mathrm{C}$. We believe the quick increase in temperature for zeolite type $\mathrm{A}$ and mordenite after $5 \mathrm{~min}$ is due to the higher iron content in these samples. The electrical conductivity of ferrous materials is generally high which causes higher microwave energy absorption with a quick increase in temperature (Tang et al. 2007; Legras et al. 2012; De Peña and Rondón 2013). The high percentage of iron in zeolite type A $(0.8 \%)$ and mordenite $(1.3 \%)$ compared to faujasite $(\mathrm{Y})(0.06 \%)$, clinoptilolite $(0.08 \%)$ and M-CLZ $(0.03 \%)$ causes the quick increase in temperature for these samples. Faujasite (Y) and clinoptilolite show relatively slower temperature rises because of the lower water and iron content in their framework. These samples reached an almost constant temperature value after about 40 min of MW irradiation. The maximum heat absorbed in faujasite (Y) was $220^{\circ} \mathrm{C}$ while clinoptilolite zeolite showed a smaller value of about $180^{\circ} \mathrm{C}$. The temperature
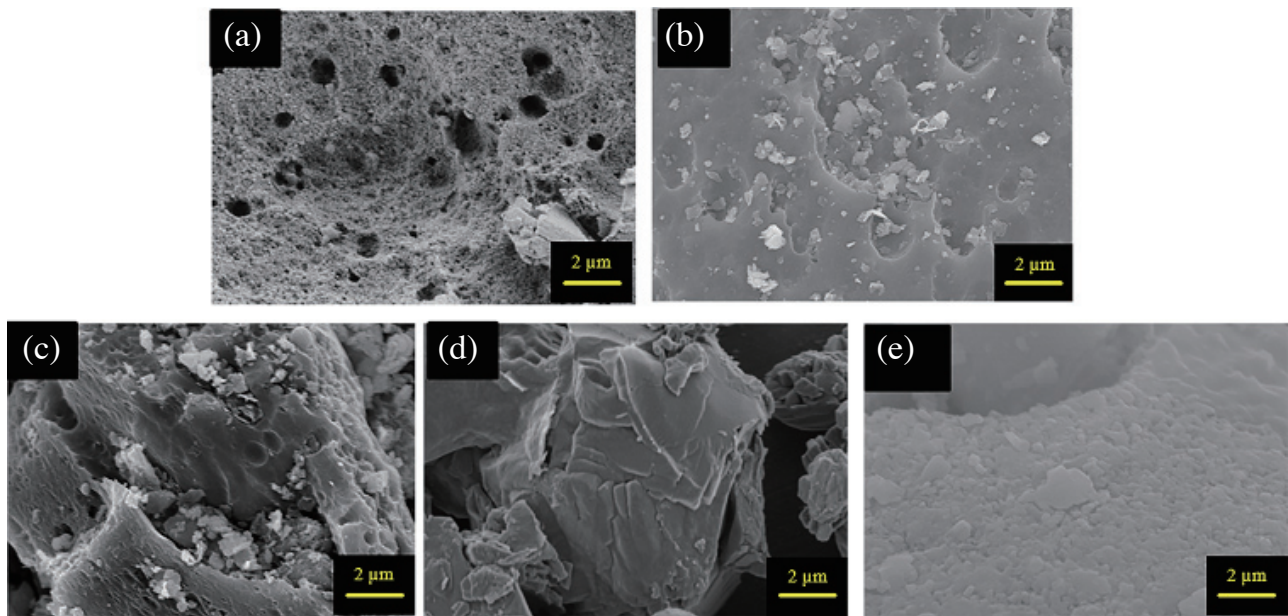

Fig. 5. FE-SEM images of zeolite samples before formaldehyde adsorption. (a) M-CLZ morphology shows well distributed pores on the surface of the zeolite, (b) Clinoptilolite zeolite, (c) Faujasite (Y), (d) Zeolite type A, (e) Mordenite zeolite morphology shows a lower number of pores on the surface. (Color online only)

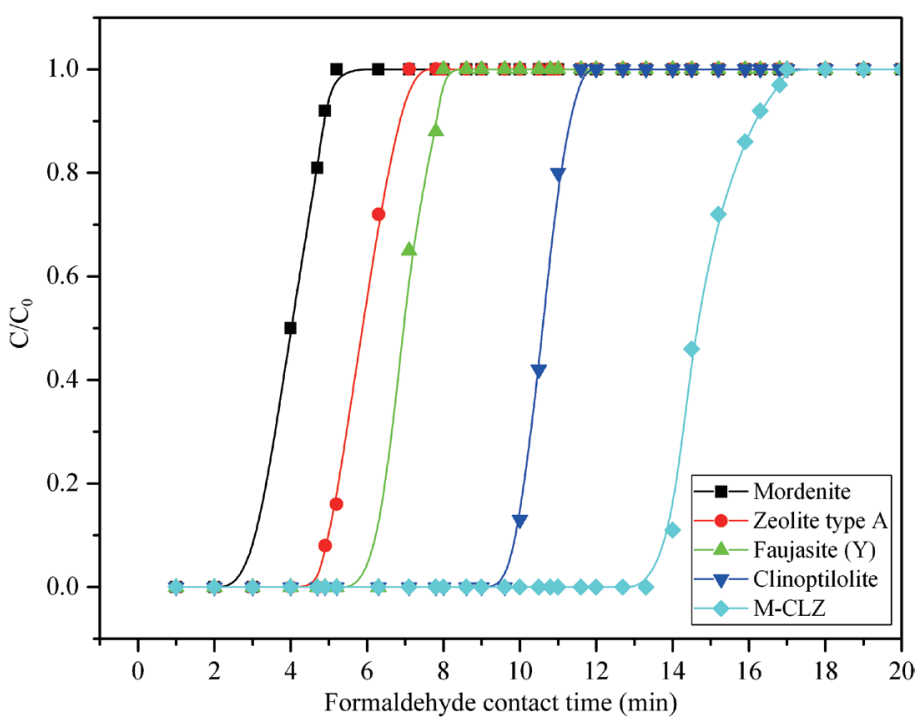

Fig. 6. Breakthrough curves of formaldehyde adsorption on various zeolites as a function of time at $25^{\circ} \mathrm{C}$. A longer breakthrough time reflects a greater adsorption capacity. (Color online only) 


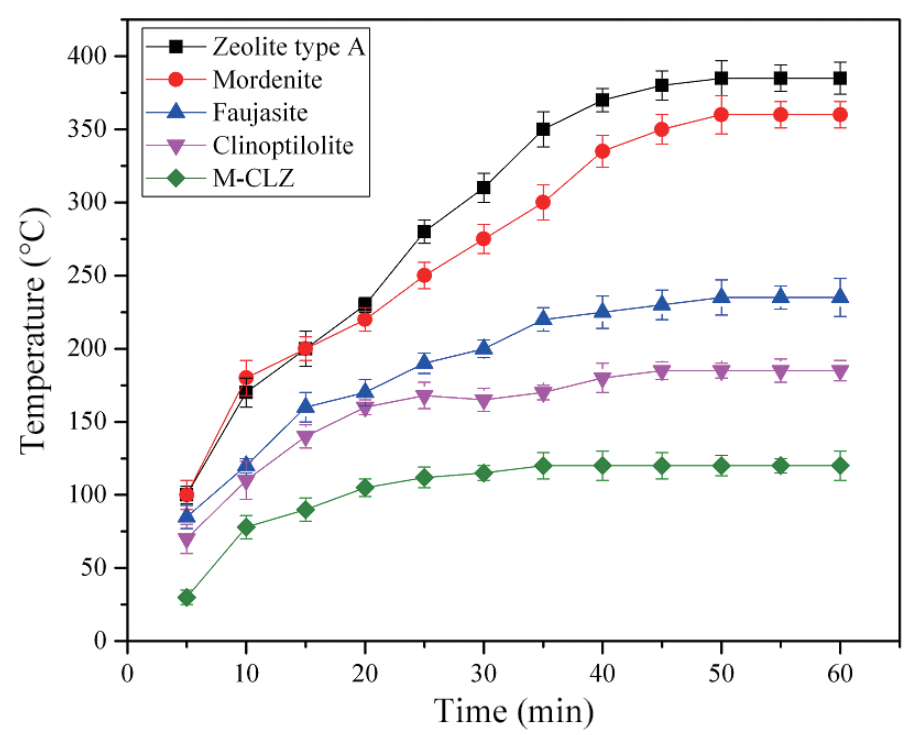

Fig. 7. Variation of adsorbent bed temperature on zeolite type A, faujasite (Y), mordenite, clinoptilolite, and M-CLZ as a function of microwave irradiation time at normal pressure and $500 \mathrm{~W}$ microwave power. (Color online only)

profile for M-CLZ showed a relatively sharp temperature inflection during the first 10 min of MW irradiation at the beginning of the experiment, which we believe is only due to a higher percentage of adsorbed formaldehyde. Formaldehyde as a polar molecule adsorbed the MW energy in a shorter time, which increased the temperature on the surface and in the internal zeolite channels. The M-CLZ temperature profile rose slowly and gradually after $10 \mathrm{~min}$ and reached the maximum of $110^{\circ} \mathrm{C}$ after $35 \mathrm{~min}$.

The desorption rate of formaldehyde from the saturated samples was determined by placing the sample in the microwave oven with power of $500 \mathrm{~W}$ and reversing the adsorption experimental conditions. Nitrogen as a carrier gas was introduced into the quartz tube containing the zeolite at the same flow rate $\left(50 \mathrm{ml} \mathrm{min}^{-1}\right)$, but from the opposite side of the adsorption experimental condition in order to remove formaldehyde from the zeolite sample.

The formaldehyde concentration in the outlet gas over time was measured with a gas chromatograph (GC-FPD). Desorption curves indicated desorption equilibrium, but the desorption time for each sample was different (Fig. 8). Mordenite and zeolite type A reached maximum desorption after 2 and $4 \mathrm{~min}$, respectively. The desorption curves for these samples showed a rapid increase at the beginning of the experiment, which we believe is due to the textural properties and surface areas of these zeolites. Mordenite and zeolite type A have low surface porosity and pore volume due to the presence of very small, spherical particles and a layered structure that causes a weak interaction between formaldehyde molecules and the void space on the sample external surfaces. The mordenite and zeolite type A temperatures reached nearly $100^{\circ} \mathrm{C}$ after 5 min of MW irradiation. At this temperature the interaction between formaldehyde molecules and the zeolite surface decreases, the separation of diffusing molecules from the surface becomes easier, and the desorption flux rate is increased.

The faujasite (Y) and clinoptilolite surface structures indicate that the crystalline top layers have high porosity; however, the total porous volume of the clinoptilolite zeolite was relatively higher than that of faujasite $(\mathrm{Y})$, as shown in the BET and FE-SEM results. We believe the longer desorption time for clinoptilolite (8 $\mathrm{min}$ ) compared to faujasite $(\mathrm{Y})$ (6.5 min) was simply due to the larger number and size of the surface pores, which directly affect the adsorption capacity. The M-CLZ desorption curve started after 6 min and gradually increased during the MW irradiation time, reaching maximum desorption after $10 \mathrm{~min}$. The formaldehyde adsorption capacity of M-CLZ is much higher compared to clinoptilolite zeolite, but the amount of desorption time for this sample did not show much difference during the MW irradiation time. This is due to the higher percentage of formaldehyde in the M-CLZ structure, which increases the dielectric constant of the sample and significantly increases MW irradiation absorption, which also caused higher temperatures (İzci and İzci 2007). The temperature curve for this sample showed a value of nearly $80^{\circ} \mathrm{C}$ after $10 \mathrm{~min}$ of MW irradiation. This temperature is enough to desorb the formaldehyde molecules captured by physical interaction on the zeolite structure. The slightly longer desorption time for M-CLZ might be due to the interconnected structure of this sample, in which both the internal zeolite structure and the microporous surfaces are continuous (Fig. 9). The interconnected microporous structure increased the adsorption capacity and the stronger interactions between the formaldehyde molecules and the internal zeolite channels led to a longer desorption time for complete formaldehyde removal. 


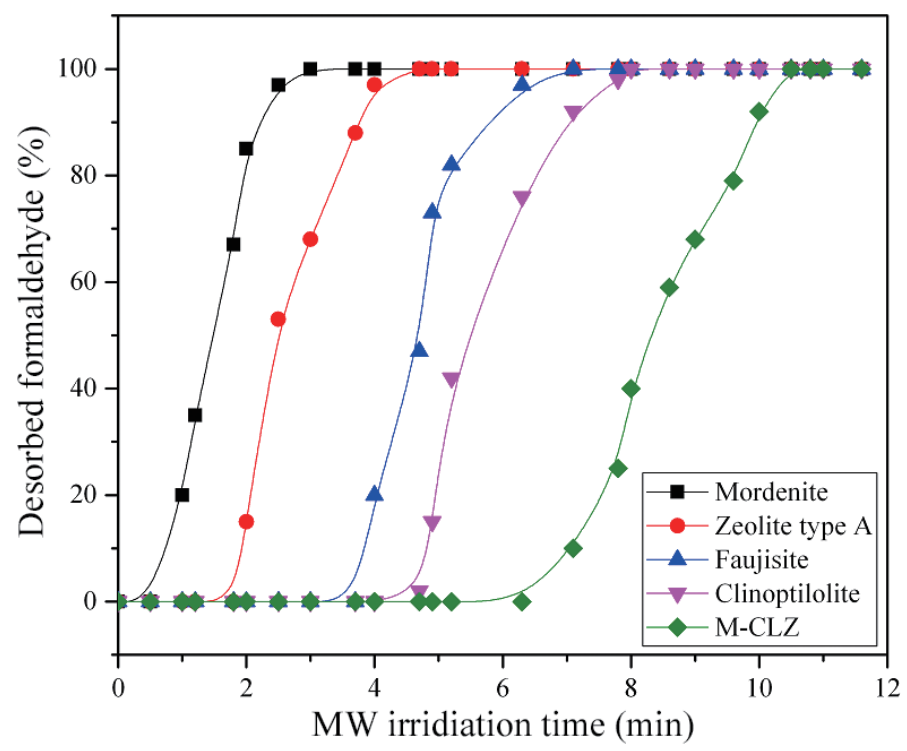

Fig. 8. Desorption efficiency of formaldehyde from studied zeolites as a function of MW irradiation time (MW power $500 \mathrm{~W}$ and normal pressure). (Color online only)
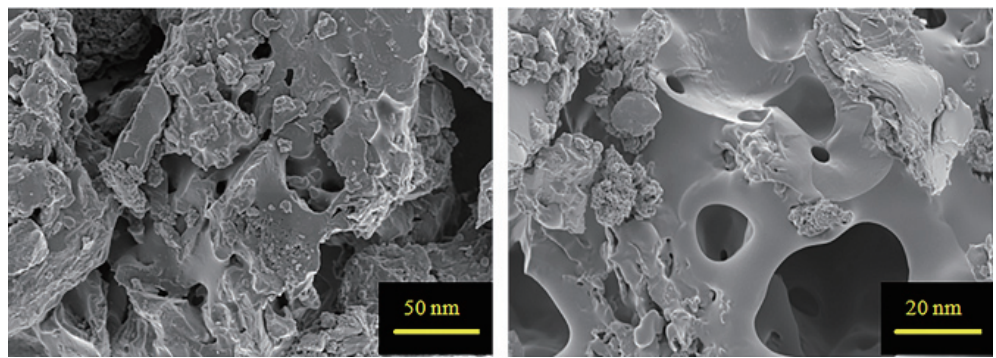

Fig. 9. FE-SEM images of the M-CLZ closely interconnected microporous structure at different magnifications. (Color online only)

It is important to stress that more research can be applied to measure the concentration of by-products such as carbon dioxide after formaldehyde desorption using MW energy since they were not considered in this particular research.

\section{CONCLUSION}

Clinoptilolite zeolite was modified with the addition of alkaline earth metals, bentonite, starch, and granite. Curing the sample at high temperature led to starch removal from the zeolite framework, resulting in the appearance of larger numbers of relatively large surface pores. The surface pores of the modified samples were measured between $1-4 \mu \mathrm{m}$. The addition of granite increased the zeolite structural hardness and prevented zeolite framework deterioration due to starch removal. The samples modified in this study showed relatively higher formaldehyde adsorption capacity of $300.5 \mathrm{mg}$ per gram of zeolite compared to that of commercially available clinoptilolite, faujasite (Y), zeolite type A, and mordenite zeolites. It is notable that the formaldehyde adsorption onto the M-CLZ increased by almost 1.6 times compared to the commercial clinoptilolite samples. Following the adsorption, a microwave heating system was used to remove the adsorbed formaldehyde from the zeolites for effective reuse. The results showed that even though the adsorption capacity of M-CLZ is much higher than that of commercial clinoptilolite zeolite, the formaldehyde desorption time did not change significantly. This might be due to the higher MW energy adsorption in the zeolite framework caused by the formaldehyde molecule polarity. It was also observed that the desorption properties of formaldehyde depended strongly on the connections between the surface pores and the internal cavities of the selected zeolites. The uniform surface pore distribution on M-CLZ and their connections with the internal structure led to a longer desorption time for this sample compared to other zeolites used in this study (10 min).

Acknowledgements This work was supported financially by the Climate Change Specialization Graduate School of Chonbuk National University. 


\section{REFERENCES}

Babarao, R., S. Dai, and D. Jiang, 2011: Effect of pore topology and accessibility on gas adsorption capacity in zeolitic-imidazolate frameworks: Bringing molecular simulation close to experiment. J. Phys. Chem. C, 115, 8126-8135, doi: 10.1021/jp1117294.[Link]

Barthomeuf, D., 2003: Framework induced basicity in zeolites. Microporous Mesoporous Mater., 66, 1-14, doi: 10.1016/j.micromeso.2003.08.006. [Link]

Bieseki, L., F. G. Penha, and S. B. C. Pergher, 2013: Zeolite A synthesis employing a Brazilian coal ash as the silicon and aluminum source and its applications in adsorption and pigment formulation. Mater. Res., 16, 3843, doi: 10.1590/S1516-14392012005000144. [Link]

Cazorla A., M. D. C. and M. Grutzeck, 2012: Indoor air pollution control: Formaldehyde adsorption by zeolite rich materials. In: Herman, C. C., S. Marra, D. Spearing, L. Vance, and J. Vienna (Eds.), Environmental Issues and Waste Management Technologies in the Ceramic and Nuclear Industries XI, Volume 176, John Wiley \& Sons, Inc., Hoboken, NJ, USA, doi: 10.1002/9781118407950.ch1. [Link]

Chen, D., Z. Qu, Y. Sun, and Y. Wang, 2014: Adsorptiondesorption behavior of gaseous formaldehyde on different porous $\mathrm{Al}_{2} \mathrm{O}_{3}$ materials. Colloid. Surface. Physicochem. Eng. Aspect., 441, 433-440, doi: 10.1016/j. colsurfa.2013.10.006. [Link]

Dávila-Rangel, J. I., M. Solache-Ríos, and J. E. NuñezMonreal, 2007: Radiation and thermal effects on cobalt retention by Mexican aluminosilicates. J. Nucl. Mater., 362, 53-59, doi: 10.1016/j.jnucmat.2006.11.010.[Link]

De Peña, Y. P. and W. Rondón, 2013: Linde type A zeolite and type Y Faujasite as a solid-phase for lead, cadmium, nickel and cobalt preconcentration and determination using a flow injection system coupled to flame atomic absorption spectrometry. Am.J. Anal. Chem., 4, 387-397, doi: 10.4236/ajac.2013.48049. [Link]

El-Maghraby, H. F., M. M. El-Omla, F. Bondioli, and S. M. Naga, 2011: Granite as flux in stoneware tile manufacturing. J. Eur. Ceram. Soc., 31, 2057-2063, doi: 10.1016/j.jeurceramsoc.2011.05.023.[Link]

Frising, T. and P. Leflaive, 2008: Extraframework cation distributions in $\mathrm{X}$ and $\mathrm{Y}$ faujasite zeolites: A review. Microporous Mesoporous Mater., 114, 27-63, doi: 10.1016/j.micromeso.2007.12.024. [Link]

Góra-Marek, K. and J. Datka, 2008: The transformation of formaldehyde on CoZSM-5 zeolites. Catal.Today, 137, 466-470, doi: 10.1016/j.cattod.2007.11.005. [Link]

Hedberg, E., A. Kristensson, M. Ohlsson, C. Johansson, P. Å. Johansson, E. Swietlicki, V. Vesely, U. Wideqvist, and R. Westerholm, 2002: Chemical and physical characterization of emissions from birch wood combustion in a wood stove. Atmos. Environ., 36, 4823-4837, doi:
10.1016/S1352-2310(02)00417-X. [Link]

Ichiura, H., T. Kitaoka, and H. Tanaka, 2003: Removal of indoor pollutants under UV irradiation by a composite $\mathrm{TiO}_{2}$-zeolite sheet prepared using a papermaking technique. Chemosphere, 50, 79-83, doi: 10.1016/S00456535(02)00604-5. [Link]

İzci, E. and A. İzci, 2007: Dielectric behavior of the catalyst zeolite NaY. Turk. J. Chem., 31, 523-530.

Johnson, S. A., E. S. Brigham, P. J. Ollivier, and T. E. Mallouk, 1997: Effect of micropore topology on the structure and properties of zeolite polymer replicas. Chem. Mater., 9, 2448-2458, doi: 10.1021/cm9703278. [Link]

Kaatze, U., R. Behrends, and R. Pottel, 2002: Hydrogen network fluctuations and dielectric spectrometry of liquids. J. Non-Crystalline Solid., 305, 19-28, doi: 10.1016/S0022-3093(02)01084-0. [Link]

Kayabalı, K. and H. Kezer, 1998: Testing the ability of bentonite-amended natural zeolite (clinoptinolite) to remove heavy metals from liquid waste. Environ. Geol., 34, 95-102, doi: 10.1007/s002540050259. [Link]

Kim, K. J. and H. G. Ahn, 2012: The effect of pore structure of zeolite on the adsorption of VOCs and their desorption properties by microwave heating. Microporous Mesoporous Mater., 152, 78-83, doi: 10.1016/j.micromeso.2011.11.051. [Link]

Koriabkina, A. O., A. M. de Jong, E. J. M. Hensen, and R. A. van Santen, 2005: Concentration and temperature dependence of the diffusivity of $n$-hexane in MFI-zeolites. Microporous Mesoporous Mater., 77, 119-129, doi: 10.1016/j.micromeso.2004.08.025. [Link]

Legras, B., I. Polaert, L. Estel, and M. Thomas, 2012: Effect of alcaline cations in zeolites on their dielectric properties. J. Microw. Power Electromagn. Energ., 46, 5-11, doi: 10.1080/08327823.2012.11689818.[Link]

Ma, C., X. Li, and T. Zhu, 2011: Removal of low-concentration formaldehyde in air by adsorption on activated carbon modified by hexamethylene diamine. Carbon, 49, 2873-2875, doi: 10.1016/j.carbon.2011.02.058. [Link]

Mohamed, M. M., T. M. Salama, I. Othman, I. Abd Ellah, 2005: Synthesis of high silica mordenite nanocrystals using $o$-phenylenediamine template. Microporous Mesoporous Mater., 84, 84-96, doi: 10.1016/j.micromeso.2005.05.017. [Link]

Muir, B., J. Matusik, and T. Bajda, 2016: New insights into alkylammonium-functionalized clinoptilolite and $\mathrm{Na}-$ P1 zeolite: Structural and textural features. Appl. Surf. Sci., 361, 242-250, doi: 10.1016/j.apsusc.2015.11.116. [Link]

Naga, S. M., F. Bondioli, M. M. S. Wahsh, and M. El-Omla, 2012: Utilization of granodiorite in the production of porcelain stoneware tiles. Ceram. Int., 38, 6267-6272, doi: 10.1016/j.ceramint.2012.04.081. [Link] 
Newsome, D. and M. O. Coppens, 2015: Molecular dynamics as a tool to study heterogeneity in zeolites - Effect of $\mathrm{Na}^{+}$cations on diffusion of $\mathrm{CO}_{2}$ and $\mathrm{N}_{2}$ in $\mathrm{Na}-$ ZSM-5. Chem. Eng. Sci., 121, 300-312, doi: 10.1016/j. ces.2014.09.024. [Link]

Omisanya, N. O., C. O. Folayan, S. Y. Aku, and S. S. Adefila, 2012: Synthesis and characterisation of zeolite a for adsorption refrigeration application. Adv. Appl.Sci. Res., 3, 3746-3754.

Sharma, P., J. Yeo, M. H. Han, and C. H. Cho, 2012: NaA zeolite cubic crystal formation and deformation: Cubes with crystalline core, simultaneous growth of surface and core crystals, and layer-by-layer destruction. RSC Advances, 2, 7809-7823, doi: 10.1039/C2RA20567J. [Link]

Solanki, P. and M. Zaman, 2012: Microstructural and mineralogical characterization of clay stabilized using calcium-based stabilizers. In: Kazmiruk, V. (Ed.), Scanning Electron Microscopy, InTech, doi: 10.5772/34176. [Link]

Solomon, S. J., G. W. Schade, J. Kuttippurath, A. Ladstätter-Weissenmayer, and J. P. Burrows, 2008: VOC concentrations in an indoor workplace environment of a university building. Indoor Built Environ., 17, 260268, doi: 10.1177/1420326X08090822. [Link]

Szostak, R., 1998: Molecular Sieves: Principles of Synthesis and Identification, Springer Science \& Business Media, 359 pp.

Tang, X., Q. Tian, B. Zhao, and K. Hu, 2007: The microwave electromagnetic and absorption properties of some porous iron powders. Mater. Sci. Eng., 445-446, 135-140, doi: 10.1016/j.msea.2006.09.008. [Link]

Teber, S., M. Elnekave, and M. Tatlier, 2010: Preparation of zeolite a coatings on copper plates by using the substrate heating method. Braz. J. Chem. Eng., 27, 619626, doi: 10.1590/S0104-66322010000400014. [Link]

Treacy, M. M. J. and J. B. Higgins, 2007: Powder pattern simulations of disordered intergrowths. Collec- tion of Simulated XRD Powder Patterns for Zeolites (Fifth Edition), Elsevier, 477-485, doi: 10.1016/B978044453067-7/50703-6. [Link]

Varela, M. T. B., S. M. Ramírez, I. Ereña, M. Gener, and P. Carmona, 2006: Characterization and pozzolanicity of zeolitic rocks from two Cuban deposits. Appl. Clay Sci., 33, 149-159, doi: 10.1016/j.clay.2006.04.006. [Link]

Walton, K. S., M. B. Abney, and M. D. LeVan, 2006: $\mathrm{CO}_{2}$ adsorption in $\mathrm{Y}$ and $\mathrm{X}$ zeolites modified by alkali metal cation exchange. Microporous Mesoporous Mater., 91, 78-84, doi: 10.1016/j.micromeso.2005.11.023. [Link]

Wirsching, U., 1981: Experiments on the hydrothermal formation of calcium zeolites. Clay Clay Miner., 29, 171183, doi: 10.1346/CCMN.1981.0290302. [Link]

Wisthaler, A., E. C. Apel, J. Bossmeyer, A. Hansel, W. Junkermann, R. Koppmann, R. Meier, K. Müller, S. J. Solomon, R. Steinbrecher, R. Tillmann, and T. Brauers, 2008: Technical Note: Intercomparison of formaldehyde measurements at the atmosphere simulation chamber SAPHIR. Atmos. Chem. Phys., 8, 2189-2200, doi: 10.5194/acp-8-2189-2008. [Link]

Yang, G. S., 2016: The effect of different moisture levels on the toluene desorption rates of modified natural zeolite during MW irradiation. J. Mater. Cy. Waste Manag., 18, 113-122, doi: 10.1007/s10163-014-0327-x. [Link]

Yildiz, N., A. Çalimli, and Y. Sarikaya, 1999: The characterization of $\mathrm{Na}_{2} \mathrm{CO}_{3}$ activated Kütahya bentonite. Turk. J. Chem., 23, 309-317.

Yılmaz, B., A. Uçar, B. Öteyaka, and V. Uz, 2007: Properties of zeolitic tuff (clinoptilolite) blended portland cement. Build. Environ., 42, 3808-3815, doi: 10.1016/j. buildenv.2006.11.006. [Link]

Zheng, Y. X., H. Ding, H. N. Luo, and M. M. Wang, 2012: Adsorption properties of formaldehyde by organic modified zeolite. Adv. Mater. Res., 581-582, 277-282, doi: $\quad$ 10.4028/www.scientific.net/AMR.581-582.277. [Link] 